\title{
Features of annual and semiannual variations derived from the global ionospheric maps of total electron content
}

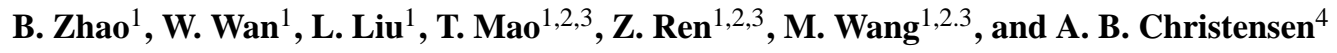 \\ ${ }^{1}$ Institute of Geology and Geophysics, Chinese Academy of Sciences, Beijing 100029, China \\ ${ }^{2}$ Wuhan Institute of Physics and Mathematics, CAS, Wuhan 430071, China \\ ${ }^{3}$ Graduate School of Chinese Academy of Sciences, Beijing, China \\ ${ }^{4}$ Space Science Applications Laboratory, Aerospace Corporation, El Segundo, California, USA
}

Received: 26 January 2007 - Revised: 23 July 2007 - Accepted: 25 October 2007 - Published: 2 January 2008

\begin{abstract}
In the present work we use the NASA-JPL global ionospheric maps of total electron content (TEC), firstly to construct TEC maps (TEC vs. magnetic local time MLT, and magnetic latitude MLAT) in the interval from 1999 to 2005. These TEC maps were, in turn, used to estimate the annualto-mean amplitude ratio, $\mathrm{A}_{1}$, and the semiannual-to-mean amplitude ratio, $A_{2}$, as well as the latitudinal symmetrical and asymmetrical parts, $A^{\prime}$ and $A^{\prime \prime}$ of $A_{1}$. Thus, we investigated in detail the TEC climatology from maps of these indices, with an emphasis on the quantitative presentation for local time and latitudinal changes in the seasonal, annual and semiannual anomalies of the ionospheric TEC. Then we took the TEC value at 14:00 LT to examine various anomalies at a global scale following the same procedure. Results reveal similar features appearing in $\mathrm{NmF} 2$, such as that the seasonal anomaly is more significant in the near-pole regions than in the far-pole regions and the reverse is true for the semiannual anomaly; the winter anomaly has least a chance to be observed at the South America and South Pacific areas. The most impressive feature is that the equinoctial asymmetry is most prominent at the East Asian and South Australian areas. Through the analysis of the TIMED GUVI columnar [O/N2] data, we have investigated to what extent the seasonal, annual and semiannual variations can be explained by their counterparts in $[\mathrm{O} / \mathrm{N} 2]$. Results revealed that the $[\mathrm{O} / \mathrm{N} 2]$ variation is a major contributor to the daytime winter anomaly of TEC, and it also contributes to some of the semiannual and annual anomalies. The contribution to the anomalies unexplained by the $[\mathrm{O} / \mathrm{N} 2]$ data could possibly be due to the dynamics associated with thermospheric winds and electric fields.
\end{abstract}

Keywords. Atmospheric composition and structure (Thermosphere-composition and chemistry) - Ionosphere (Mid-latitude ionosphere, Equatorial ionosphere)

Correspondence to: B. Zhao

(zbqjz@mail.igcas.ac.cn)

\section{Introduction}

Early investigations revealed that the F2 layer is "anomalous" rather than simply controlled by the solar zenith angle, according to the prediction of Chapman theory (Appleton and Naismith, 1935). The well-known temporal anomalies observed are the winter anomaly or seasonal anomaly (that noontime $\mathrm{NmF} 2$ values at mid-latitudes are larger in winter than in summer), the semiannual anomaly (that $\mathrm{NmF} 2$ is greater at equinox than at solstice), the annual or nonseasonal anomaly (that by taking the Northern and Southern Hemispheres together, NmF2 is greater around December solstice than around the June solstice both by day and by night; an alternative description is that the seasonal anomaly is less evident in the Southern Hemisphere than the Northern). Though in some papers, "variation" was used to replace the term "anomaly", the two concepts are different. Any trend with a period of a year or one half of a year can be called an annual or semiannual variation, while the annual and semiannual anomalies only refer to the above description in the bracket. Any trend with a seasonal asymmetry can be named a seasonal variation while a seasonal anomaly only denotes a winter anomaly. Many authors used the annual and semiannual variation to denote seasonal, semiannual and annual anomalies for convenience. To avoid a misunderstanding one knows that the meaning of the variation is more extensive than that of the anomaly. Since discovering these anomalies, they have become very prominent subjects and attract the interest of many authors. Yonezawa and Arima (1959) and Yonezawa (1971, 1972) scrutinized the relationships between the winter anomaly, the annual anomaly, and the semiannual anomaly at mid-low latitudes with the solar activity and geomagnetic latitude. Torr and Torr (1973) constructed maps with observed foF2 data to show the global distributions of these anomalies mentioned above. Balan et al. $(1998,2000)$ studied the altitude dependence of the seasonal anomaly and found the existence of

Published by Copernicus Publications on behalf of the European Geosciences Union. 
equinoctial asymmetries (the electron density in one equinox being larger than that in the other equinox) in the ionosphere and thermosphere during solar maximum period by using the Japanese MU radar data. Ma et al. (2003) derived features of the semiannual anomaly at different latitudes and longitudes using worldwide ionosonde data from 1974-1986.

Many theories have been proposed to explain the variations of the F2-layer anomalies, as reviewed by Rishbeth (1998). Among these various theories, the "chemical explanations" proved to be rather reasonable and have been accepted to some extent. Rishbeth and Setty (1961) and Wright (1963) recognized that the change in the chemical compositions in the upper atmosphere, such as the atomic-molecular ratio [O/N2], could mainly account for the variation of $\mathrm{NmF} 2$ during the daytime. Subsequently, Johnson (1964) and King (1964) suggested that the thermospheric circulation from the summer hemisphere to the winter one could affect the [O/N2] ratio and finally change NmF2. Since the 1980s, numerical methods have been applied to investigate the electron density variations in the ionosphere. Based on the global thermospheric circulation theory, Fuller-Rowell and Rees (1983) reproduced the seasonal variation of $\mathrm{NmF} 2$. After considering the offset of the geographic and geomagnetic poles, Millward et al. (1996) tried to explain the longitude differences in seasonal and semiannual characteristics at mid-latitudes. Fuller-Rowell (1998) proposed a mechanism named "thermospheric spoon" to interpret the semiannual variation in the ionosphere. He suggests that the global-scale, interhemispheric circulation at solstices acts like a huge turbulent eddy in mixing the major species. The effect causes less diffusive separation of the species at solstices, which tends to a rise in the molecular nitrogen and oxygen densities and a reduction in the atomic oxygen density. With a coupled thermosphereionosphere-plasmasphere model (CTIP), Zou et al. (2000) re-examined the global thermospheric circulation theory and how far the semiannual anomaly could be explained by this theory without invoking other causes. Thereafter, Rishbeth et al. (2000) gave a detailed physical discussion.

Hitherto, most studies of the F-layer anomaly have used data on NmF2 from ionosonde stations (e.g. Yonezawa, 1971; Torr and Torr, 1973; Yu et al., 2004). However, some measurements have shown that these anomalies vary at different altitude regimes. Observational evidence indicates that there is no winter anomaly in the topside ionosphere, whereas it is significant in the F-region (e.g. Balan et al., 1998; Torr and Torr, 1973; Su et al., 1998; Zhao et al., 2005; Liu et al., 2007). Moreover, observational evidence also shows that the annual anomaly is very strong in the topside ionosphere, as compared with the bottomside ionosphere ( $\mathrm{Su}$ et al., 1998). It is reasonable to imagine that the total electron content (TEC) and the integral of electron density height profile $\mathrm{N}(\mathrm{h})$ might have different characteristics as compared with those derived from the NmF2. Further support is provided by the fact that the annual anomaly predominates over the seasonal variations for TEC (Titheridge and Buonsanto,
1983) compared to the small annual component for $\mathrm{NmF} 2$.

In recent years, a database of TEC in the ionosphere and plasmasphere, derived from a worldwide network of global positioning system (GPS) observations, has been used to investigate the local and regional characteristics of various anomalies (Huang and Cheng et al., 1996; Unnikrishnan et al., 2002; Wu et al., 2004). Since the early 1990s, a worldwide network of permanent GPS tracking stations has rapidly grown under the management of the International GNSS (Global Navigation Satellite Systems) Service, known as IGS. In May 1998, IGS created the Ionosphere Working Group (Feltens and Schaer, 1998), and soon after five different centers started computing and making available several GPS-derived ionospheric products, mainly two-dimensional world-wide grids of vertical total electron content (VTEC) and differential code biases (DCBs) for every satellite and many receivers in the network. To make feasible interchanges and comparisons, the so-called IONEX (Ionosphere Map Exchange) standard format was established (Schaer et al., 1998). In this study, we use the global ionospheric maps (GIMs) developed by the JPL because of its relatively high reliability and accuracy. There is a rich literature describing the development of JPL GIM (e.g. Mannucci et al., 1998), as well as their use in studies of ionospheric behavior, particularly under disturbed conditions (Ho et al., 1996; Pi et al., 1997). The GPS system and the JPL GIMs derived from its data have become a standard ionospheric diagnostic tool, and are particularly useful for our study.

Mendillo et al. (2005) have found the annual anomaly in TEC to be a global characteristic by using GIMs data of the year 2002. Here, to some extent, we are about to expand their work and explore the global feature of the principle F2layer anomalies, including the winter anomaly, the semiannual anomaly and the annual anomaly. First, we have attempted to find out how these anomalies varied under different magnetic local time (MLT) and different solar activity, in which we compare them with the magnitudes of the annual and semiannual anomaly by using data from the GUVI experiment aboard the TIMED satellite. Then we studied the global distribution of the amplitudes of various anomalies during the daytime under different solar activity. In the Discussion section, current theories and mechanisms were used to give possible explanations of various anomalies. We hope the work could help us in achieving comprehensive insight into the complexities of F2-layer behavior.

\section{Magnetic local time variation of the anomalies}

\subsection{Data resources and analysis method}

We used data spans from 1999-2005 which can be downloaded from the website http://cddis.gsfc.nasa.gov. Before day 307, 2002 all JPL IONEX files provided include 12 VTEC maps, starting from 01:00 UT to 23:00 UT, due to 


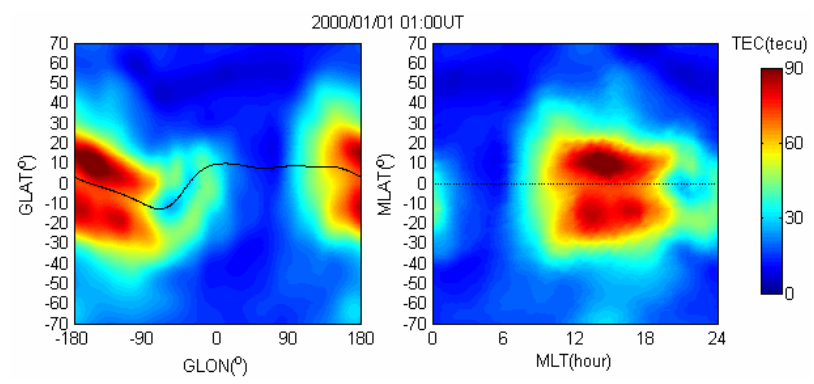

Fig. 1. An example of GIM being transformed from an Earth-fixed geographic frame into a MLAT-MLT frame at 01:00 UT on 1 January 2000 .

the fact that each new daily file contains ionospheric information covering not only 22 but $24 \mathrm{~h}$. The new daily file includes 13 VTEC maps, starting from 00:00 UT to 24:00 UT, in order to facilitate the data interpolation. Each map is created in an Earth-fixed reference frame with geographic longitude ranging from $-180^{\circ}$ to $180^{\circ}\left(5^{\circ}\right.$ resolution) and latitude from $-87.5^{\circ}$ to $87.5^{\circ}$ (2.5 $5^{\circ}$ resolution). For our purpose in constructing TEC maps, we follow the works of Codrescu et al. (2001) and Jee et al. (2004) to estimate the TEC maps in the plane of magnetic local time (MLT) vs. magnetic latitudes (MLAT) using quasi-dipole coordinates (Richmond, 1995). Thus, we first transform the geographic longitude and latitude into MLT (00:00 24:00) and MLAT $\left(-70^{\circ} \sim 70^{\circ}\right)$, and then divide the MLT vs. MLAT plan into mesh grids with grid length $\mathrm{dMLT}=0.5$ hour and $\mathrm{dMLAT}=2.5^{\circ}$. We calculate the average TEC in each bin as the grid TEC values. We estimate the TEC maps in the plane of magnetic local time (MLT) vs. magnetic latitudes (MLAT) by virtue of the tilted dipole field. Figure 1 gives an example of GIM being transformed from an Earth-fixed into a MLAT-MLT frame. The most prominent feature of the TEC maps is the well-known double crest structure of the ionospheric equatorial anomaly. The equatorial anomaly crests usually appear in the magnetic latitude about $\pm 10^{\circ} \sim 15^{\circ}$ during almost the entire daytime, with a maximum value at post noon. For each day there are 12 or 13 maps and we make an average to give one map a day which is enough for the investigation of the ionospheric climatology. To extract the amplitudes of the annual and semiannual variations, a yearly TEC variation is represented by the sum of the yearly average TEC 0 , annual TEC 1 and semiannual TEC2 components:

$$
\begin{aligned}
& \mathrm{TEC}(\text { mlat }, d)=\mathrm{TEC} 0+\mathrm{TEC} 1+\mathrm{TEC} 2 \\
& \quad=\mathrm{TEC} 0\left\{1+A_{1} \times \cos \left[2 \pi\left(d-d_{1}\right) / T\right]\right. \\
& \left.\quad+A_{2} \times \cos \left[4 \pi\left(d-d_{2}\right) / T\right]\right\} \\
& \\
& A_{1}=\mathrm{TEC} 1 / \mathrm{TEC} 0 ; A_{2}=\mathrm{TEC}_{2} / \mathrm{TEC} 0
\end{aligned}
$$

where $d$ is the day number and $T$ ( $T=365$, and 366 for leap year) is the total days of a year. TEC0 is the yearly average
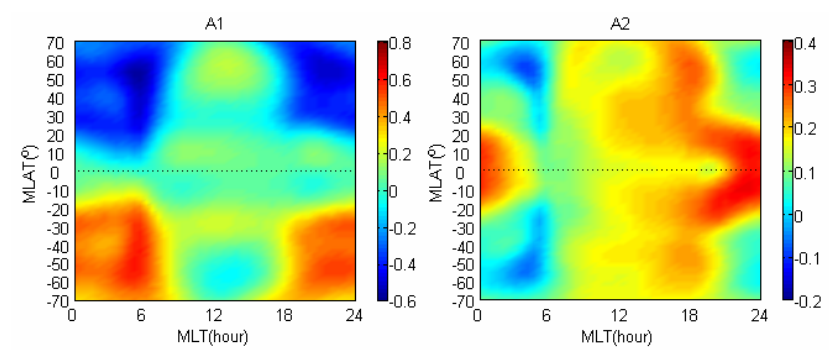

Fig. 2. Annual and semiannual indices $A_{1}$ and $A_{2}$ for the year 2000 have been estimated as functions of MLT and MLAT, according to the Eq. (1). In the left panel of Fig. 2, positive values indicate that the maximum value of the yearly TEC appears at the December solstice and negative denotes the June solstice.

value of TEC. $A_{1}$ and $A_{2}$ are, respectively, the relative amplitudes of the TEC annual and semiannual components; $d_{1}$ and $d_{2}$ are the corresponding phases, respectively, denoting the winter solstice and vernal equinox and vary slightly from year by year. For the year 1999, 2002 and 2003, $d_{1}$ is 22 December and for the remaining year 21 December. For the year 1999 and 2003, $d_{2}$ is 21 March while for the remaining year 22 March.

\subsection{Results of the GIM}

Displayed in Fig. 2 are the annual and semiannual indices, $A_{1}$ and $A_{2}$, for the year 2000 which have been estimated as functions of MLT and MLAT, according to the Eq. (1). In the left panel of Fig. 2, a positive value means that the maximum value of the yearly TEC appears at the December solstice and negative denotes the June solstice. It is shown that $A_{1}$ has a clear local time variation. The summer maximum appears from the sunset, 18:00 MLT, to after the sunrise, 08:00 MLT. At night, the overall summer to winter prevailing wind will, respectively, enhance and retard the equatorward winds in the summer and winter hemisphere, which raise or lower the F2-layer and thus increase and decrease the NmF2 (Rishbeth, 1998). It should be noticed that a prominent maximum occurs at around sunrise time, 06:00 MLT. This is understood to be due to the control of the F2-layer by production and not by diffusion, which varys markedly due to the seasonal change. Winter maximum, namely the winter anomaly, appears at middle and mid-high latitudes between 10:00-16:00 MLT, and the maximum value occurs at around 14:00 MLT. The main cause of the winter anomaly is that the vertical wind does change the chemical composition (Rishbeth et al., 1987). As part of the entire atmosphere circulation, upwelling air that occurs at low latitudes and in summer hemisphere, due to the pressure divergence, will decrease the $[\mathrm{O} / \mathrm{N} 2]$ and increase the mean molecular mass, thus decreasing the electron content. Subsequently, this molecule-enriched air will be transported by the horizontal summer to winter prevailing wind and descend at mid-high 

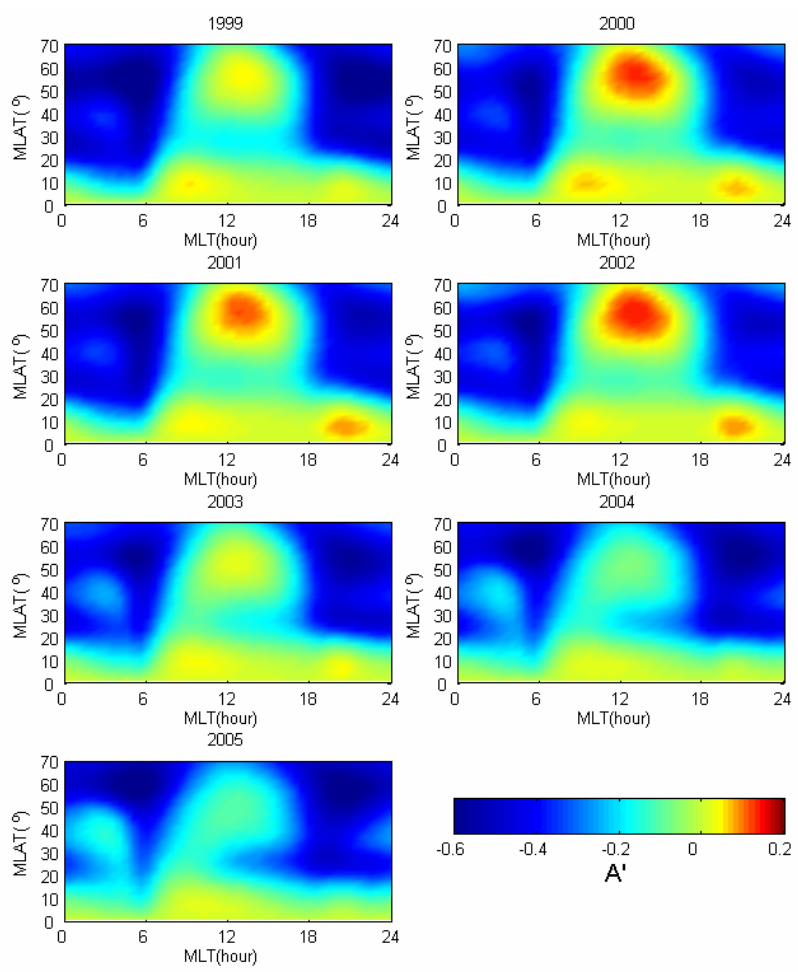

Fig. 3a. Distribution of (a) symmetrical index $A^{\prime}$, defined as $\left(A_{1}\right.$ (MLAT) $-A_{1}(-$ MLAT $\left.)\right) / 2$ (b) asymmetrical index $A^{\prime \prime}$, defined as $\left(A_{1}\right.$ (MLAT) $+A_{1}(-$ MLAT $\left.)\right) / 2$ and (c) semiannual component $A_{2}$ for the year 1999-2005.

latitude, meeting the subsidiary circulation that originated from the winter auroral oval. The downwelling air will increase the $[\mathrm{O} / \mathrm{N} 2]$ and decrease the mean molar mass, thus increasing the electron content (Rishbeth, 1998). The right panel of Fig. 2 depicts the variation of the semiannual index $A_{2}$, which has a clear latitudinal and local time dependence. Generally, there is a small, semiannual background component distributed from equatorial region to the high latitudes. However, a significant $A_{2}$ occurs after 12:00 MLT, where the maximum value appears at sub-equatorial regions during the period 20:00-24:00 MLT. To further explore the characteristics of the various anomalies, we define the symmetrical and asymmetrical indices as $A^{\prime}=\left(A_{1}\right.$ (MLAT $\left.)-A_{1}(-\mathrm{MLAT})\right) / 2$ and $A^{\prime \prime}=\left(A_{1}(\mathrm{MLAT})+A_{1}(-\mathrm{MLAT})\right) / 2$, in which the former denotes the amplitude of the seasonal variation and the latter represents the annual anomaly. Thus, plentiful properties of the ionospheric TEC climatology were found in these index maps from the year 1999 to 2005, as shown in Fig. 3.

The distribution of $A^{\prime}$, shown in Fig. 3a, manifests that the noon winter anomaly has a clear solar activity dependence. During the low solar activity year, the noon anomaly at midlatitudes is absent, with $A^{\prime \prime}$ being negative. At moderate solar activity, for example 1999 and 2003, $A^{\prime \prime}$ is no more than $5 \%$ (5\% means 0.05 and the same for the following value)
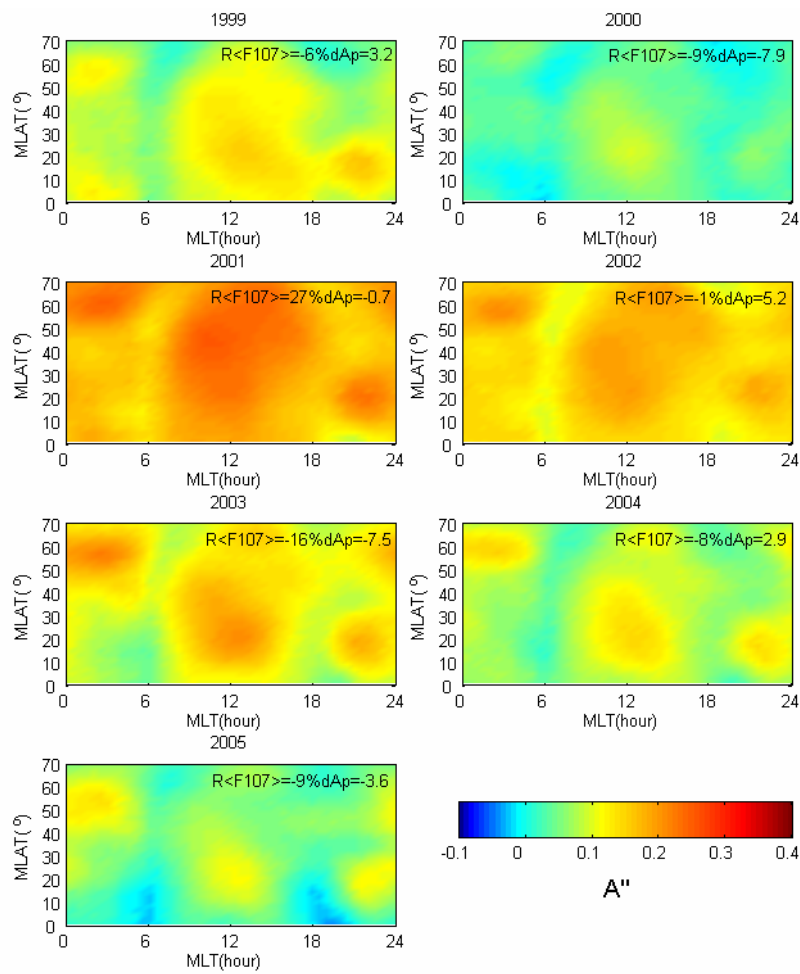

Fig. 3b. Continued.

and during high solar activity, $A^{\prime}$ is $15 \%$. Figure $3 \mathrm{~b}$ displays the distribution of $A^{\prime \prime}$. Since large differences in solar activity between the two solstitial months might result in the annual anomaly, we calculate the relative change in the mean solar radiation F107 index, $R_{<\mathrm{F} 107>}\left(R_{<\mathrm{F} 107>}=\left(\overline{\mathrm{F} 107}_{\mathrm{Dec}}-\right.\right.$ $\left.\overline{\mathrm{F}} 107_{\mathrm{Jun}}\right) /{\overline{\mathrm{F}} 107_{\mathrm{Jun}}} \times 100 \%$ ) between December and June, respectively. Noting that typically 1 unit of geomagnetic daily index Ap decreases NmF2 by only 1\% (e.g. Rishbeth and Mendillo, 2001), and that the change in TEC should be similar, we also calculate the difference of mean values of the geomagnetic Ap index, $\mathrm{dAp}\left(d A p=\overline{A p}_{\mathrm{Dec}}-\overline{A p}_{\text {Jun }}\right)$ between the two solstitial months. From the figure, we can see that the large value of $A^{\prime \prime}$ at the year 2001 should result from the $27 \%$ solar flux difference between December and June. $A^{\prime \prime}$ is weak at the sunrise and sunset sector, acting as a boundary to separate daytime and nighttime positive $A^{\prime \prime}$ appearing nearly at all the latitudes. Except for the year 2000, $A^{\prime \prime}$ is shown to be more evident during high solar activity, such as 2002 and least evident during low solar activity 2005, which may suggest a dependence on the solar activity level. Figure $3 \mathrm{c}$ shows that the semiannual component $A_{2}$ increases significantly with the solar activity. During low and moderate solar activity, $A_{2}$ does not exceed 20\% during 09:00-18:00 MLT, while during high solar activity within the same period $A_{2}$ reaches $30 \%$. In the post-sunset period at low latitudes a pronounced double peak structure is manifested in $A_{2}$, where it even reaches $40 \%$ during a high solar activity year while being absent during low and moderate solar activity year. 


\subsection{Results in neutral O/N2 from GUVI observations}

We take as a first approximation that photochemical equilibrium conditions prevail up to the F-region peak. In this case the maximum ionization is given by $\mathrm{Nmax} \sim q / \beta \sim[\mathrm{O} / \mathrm{N} 2]$ (Rishbeth, 1998). In this study, we want to find out whether the neutral gas composition at F-layer heights has the seasonal, semiannual and annual anomalies of the comparable magnitude, as that which appears in the TEC, without considering the effects of the transport processes. We use the $[\mathrm{O} / \mathrm{N} 2]$ data measured from the global ultraviolet imager on the TIMED satellite (Christensen et al., 2003). The values of [O/N2] refer to column density ratios above levels of the fixed $\mathrm{N} 2$ column content $\left(10^{21} \mathrm{~m}^{-2}\right.$ or $\left.10^{17} \mathrm{~m}^{-2}\right)$, derived from airglow observations in the $140-250 \mathrm{~km}$ height range; see Christensen et al. (2003) and Strickland et al. (2004) for details of the experiment and analysis techniques. Strickland et al. (2001) showed that the electron concentration varies with this column density ratio. These are shown as global maps in Strickland et al. (2004), depicting the global distribution of columnar [O/N2] at local noon on four particular days in 2002-2003, which were geomagnetically quiet, and have similar levels of solar flux index F107.

The TIMED satellite was launched on 7 December 2001 into a $630 \mathrm{~km}, 74.1^{\circ}$ inclination circular orbit with a $97.8 \mathrm{~min}$ period. The orbital precession rate is such that the beta angle (the angle between the Earth-Sun vector and the orbital plane) passes through zero every 120 days, so the local time of the orbit varies with this periodicity. As a consequence, GUVI samples all local solar times every 60 days, counting ascending and descending node orbits. The data have been transformed into the MLAT vs. MLT frame and a 60-day moving average has been employed to preserve the spatial and temporal information. Four years of data during 20022005 have been utilized to extract the seasonal, semiannual and annual amplitudes with Eq. (1). Figure 4 gives the distribution of the columnar [O/N2] centered at equinox and solstice during the year 2003. The distribution presents a clear seasonal variation which shows that $[\mathrm{O} / \mathrm{N} 2]$ is low in the summer hemisphere and high in the winter hemisphere at middle-high latitudes. Data during the 08:00-16:00 MLT interval is shown with full resolution, to facilitate the study of various anomaly changes.

Figure 5 displays the magnitudes of the symmetrical index $A^{\prime}$, the asymmetric index $A^{\prime \prime}$ and the semiannual variation $A_{2}$ for [O/N2] from 2002 to 2005 , respectively. The magnitude of $A^{\prime}$ has a clear solar dependence that varies from $0.3-0.45$ with increased solar activity, and is much larger than that for the winter anomaly in TEC. This is probably because the daytime summer-to-winter wind will reduce the winter anomaly effect by uplifting and depressing the F-layer peak. The difference may also partly result from the different height range measured for these two parameters. The overall value of the distribution of $A^{\prime \prime}$ is $\sim 0.1$, less than that of TEC at $\sim 0.15$, which partly can be used to explain the
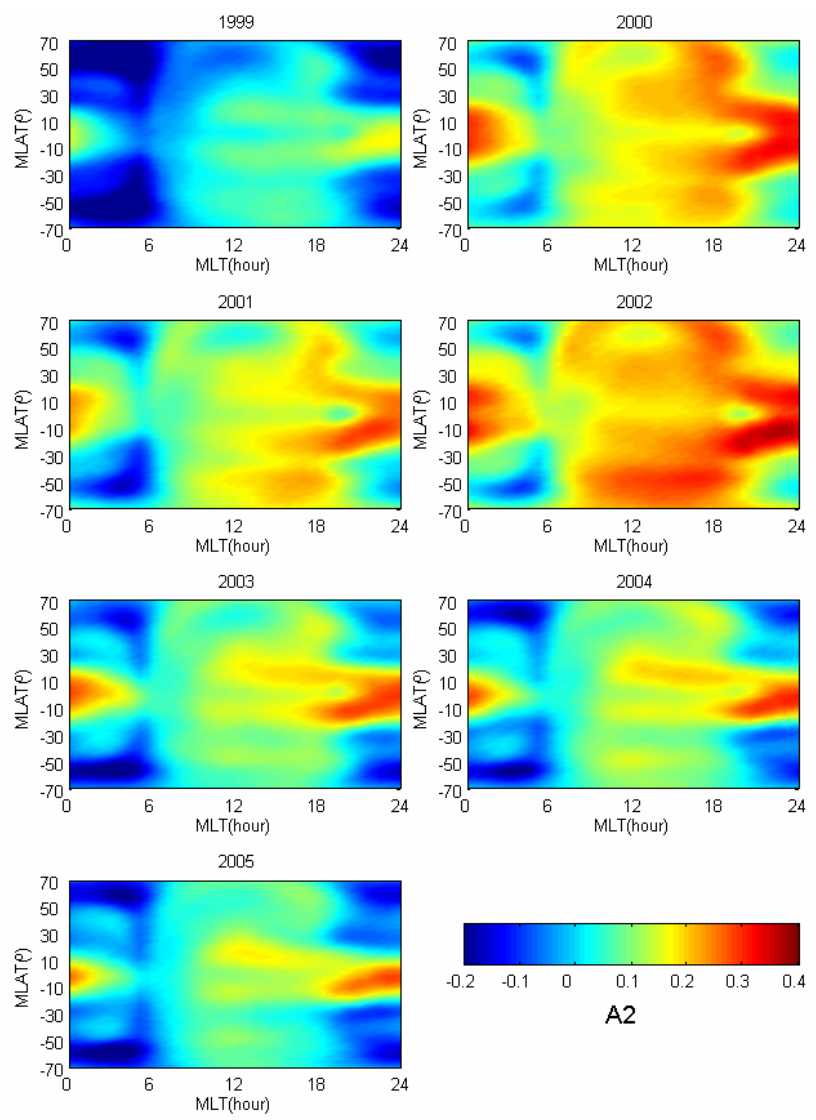

Fig. 3c. Continued
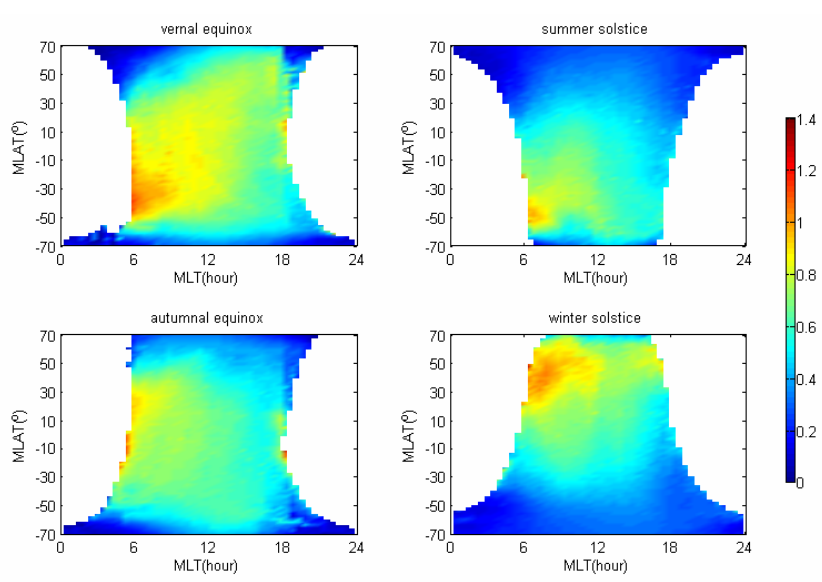

Fig. 4. Distribution of the columnar [O/N2] centered at equinox and solstice during the year 2003 .

annual anomalies in TEC. The semiannual variation $A_{2}$ is shown with a considerable magnitude of about $0.1-0.2$, especially at middle and mid-low latitudes, providing some evidence that the TEC semiannual variation is related to semiannual changes in thermospheric composition. Furthermore, the magnitude of the semiannual variation in $[\mathrm{O} / \mathrm{N} 2]$ in the 

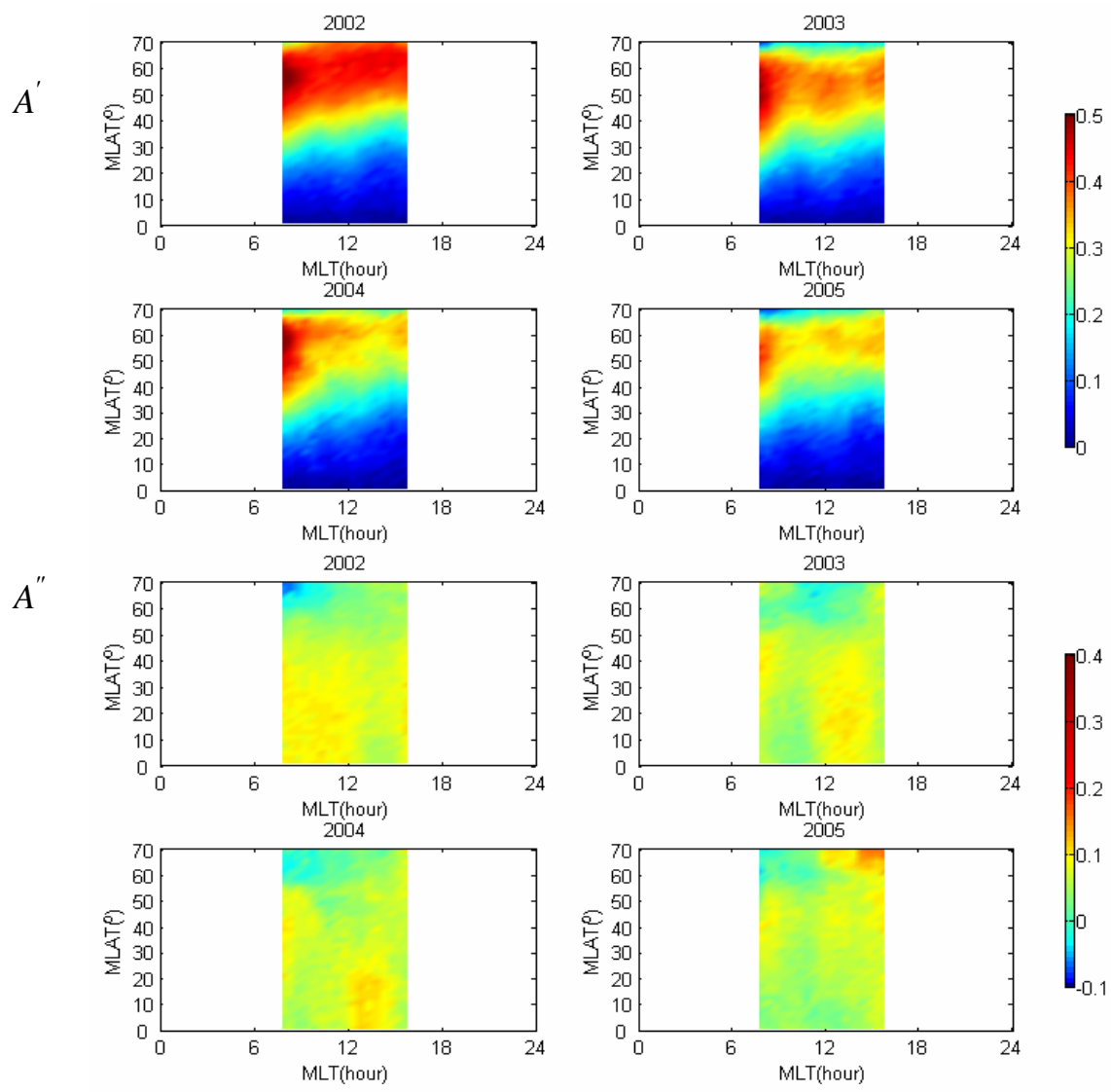

$A_{2}$
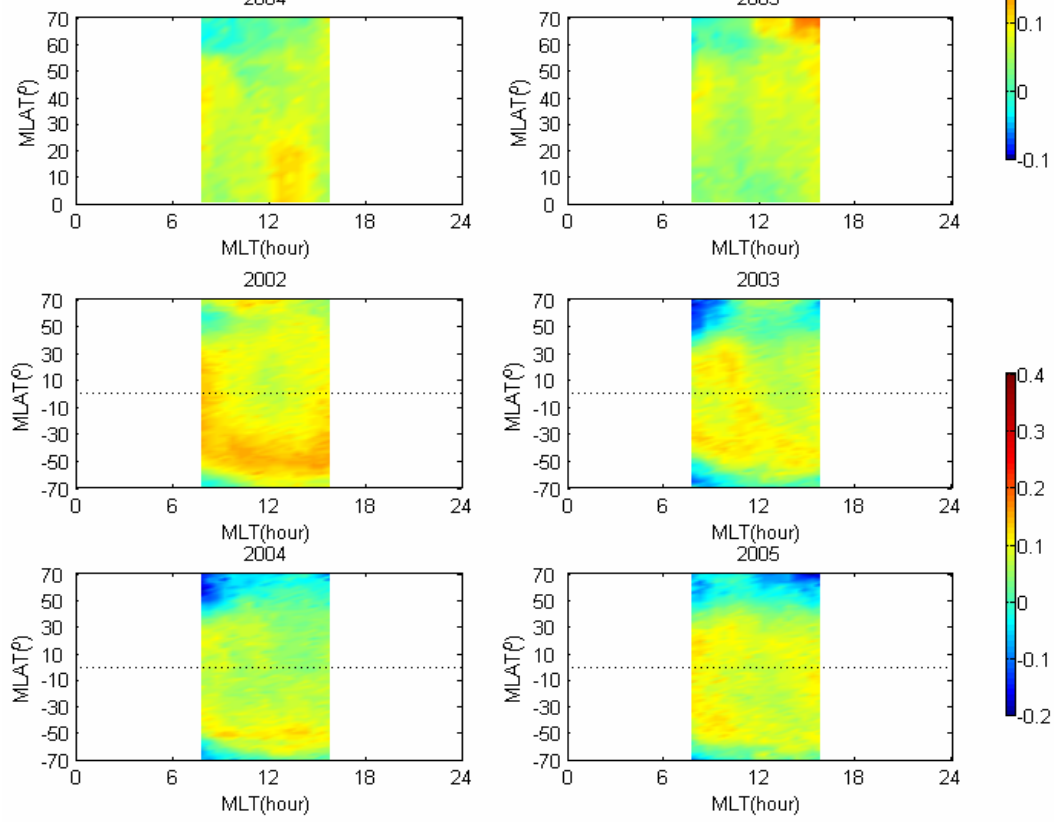

Fig. 5. From the top to bottom panel are the magnitudes of $A^{\prime}, A^{\prime \prime}$ and $A_{2}$ for GUVI [O/N2] during 08:00-16:00 MLT from 2002 to 2005, respectively, corresponding to Fig. 3a, b and c.

northern mid-high latitudes is weaker than that in the Southern Hemisphere. This feature can be also identified in the distribution of $A_{2}$ in TEC, as shown in Fig. $3 \mathrm{c}$ at around the MLT=12:00 sector in the mid-high latitude. It is understood that the results of the TEC and [O/N2] are sometime uncorrelated because we do not consider the transport process. The ionosphere is not only controlled by the solar zenith angle but also constrained by the magnetic field. For example, a strong semiannual variation at the double crest region after sunset may be associated with the semiannual variation of the equatorial $E \times \mathrm{B}$ drift. Detailed discussion is given in the Discussion section.

\section{Longitude variation of the annual and semiannual variation at 14:00 LT}

As a matter of fact, organizing the data in the MLAT-MLT coordinate removes the longitudinal difference of the various 
anomalies. As is shown in the above section, the winter anomaly is most pronounced during 14:00 LT, so we take the TEC value at 14:00 LT to examine various anomalies at a global scale. The analysis of the data is the same as the previous local time variation by applying Eq. (1) but without limiting the phases $d_{1}$ and $d_{2}$. Equation (1) can be expanded by the following form:

$$
\begin{aligned}
& \text { TEC }(\text { mlat }, d)=\operatorname{TEC} 0\left\{1+A_{1} \times \cos \left[2 \pi\left(d-d_{1}\right) / T\right]\right. \\
& \quad+A_{2} \times \cos \left[4 \pi\left(d-d_{2}\right) / T\right] \\
& =\text { TEC } 0\{1+C 1 \times \cos [2 \pi d / T]+C 2 \times \cos [4 \pi d / T] \\
& \quad+S 1 \times \sin [2 \pi d / T]+S 2 \times \sin [4 \pi d / T]\} .
\end{aligned}
$$

$A_{1}=\sqrt{C_{1}^{2}+S_{1}^{2}}$ and $d_{1}=\tan ^{-1}\left(S_{1} / C_{1}\right)$ are the amplitude and phase of annual variation, respectively, and $A_{2}=\sqrt{C_{2}^{2}+S_{2}^{2}}$ and $d_{2}=\tan ^{-1}\left(S_{2} / C_{2}\right)$ are the amplitude and phase of the semiannual variation, respectively. We use the method of regression analysis to calculate the amplitudes and phases of the semiannual variation.

Panels (A) and (B) of Fig. 6 illustrate the relative amplitudes of the annual and semiannual variations. Panel (C) shows the phase of the annual variation (C) and panel (D) gives the phase of maximum value of TEC. Here we did not display the phase of the semiannual variation because $d_{2}$ is during either a vernal month or an autumnal month, which provides no valuable information. In order to facilitate our description, we define March, April and the first half part of May as $M$-month. June, July, August and the last half part of May are denoted as $J$-month, and September, October and the first half part of November as $S$-month, and December, January, February and the last half part of November as $D$-month. In panels (C) and (D), different areas are filled with different colors according to their phase distribution. Combining (A)-(C), we note the following features: (1) the amplitude of the winter anomaly is prominent at middle and mid-high latitudes in the Northern Hemisphere, which is clearly modulated by the solar activity. More area is covered with the winter anomaly at Northern Hemisphere during higher solar activity year. The most striking area of winter anomaly is in the North America region near the north magnetic pole. (2) The winter anomaly is much less prominent in the Southern Hemisphere. The relative large values appear at the south Indian Ocean and Australian area, near the south magnetic pole during the year 2000. (3) The amplitude during normal conditions, i.e. where the summer value is greater than the winter value, is most striking at middle latitudes of the South Pacific and Atlantic Ocean areas, and is more evident during moderate and low activity. (4) The amplitude of semiannual variation is most notable at the South America and Far East areas, which are far away from the magnetic pole region. (5) The amplitude of the semiannual variation is more notable south of South America than in the Far East region. (6) The amplitude of the semiannual variation is very weak near the magnetic pole region. (7) The semiannual variation is likely symmetrical to the magnetic equator in the middle to low latitudes. Among the above conclusion, (1) and (2) constitute the annual anomaly where the winter anomaly is more prominent in the Northern Hemisphere than in the Southern Hemisphere.

Panel (D) actually manifests the feature of an equinox asymmetry. Except in the North America region, South Pacific and Atlantic Ocean areaa, which have a strong annual variation, most of the world is characterized by a prominent semiannual variation. The maximum value of the yearly TEC appears mainly during vernal months except, to the years 1999 and 2001. We calculate the ratio of mean TEC of $M$ months to $S$ month $R_{<\mathrm{TEC}>}$, as illustrated in panel (E). The ratio of mean F107 of $M$ months to $S$ month $R_{<\text {F107> for }}$ each year is also given in the map. It is shown that during the years 1999 and 2001, $R_{<\mathrm{F} 107>}$ is 0.81 and 0.77 , respectively, which should be responsible for the value $R_{<\mathrm{TEC}>}<1$. For 2000, the most striking equinox asymmetry for the condition $R_{<\mathrm{TEC}>}>1$ occurs in two regions. The first one lies along the band between the magnetic latitudes $30^{\circ}-50^{\circ}$ in the Northern Hemisphere which is clearly evident in the Far East region. Note that in the high latitudes of Europe and Russian, near the $70^{\circ}$ North, $R_{<\mathrm{TEC}>}$ is also significant during 2000. The second one is located in the southern Indian Ocean and Australian regions. In these regions, $R_{<\mathrm{F} 107>}$ varies between 0.97 and 1.12 while $R_{<\mathrm{TEC}>}$ ranges from 1.3-1.5. In fact, though $R_{<\mathrm{F} 107>}$ is relatively small during 1999 and 2001, the $R_{<\mathrm{TEC}>}$ of the above region remains at 1, which implies that the TEC value in $M$ months is larger than that in $S$ Months.

\section{Discussions}

\subsection{Explanation of the semiannual and annual anomalies}

Since the solar EUV input is greatest at low latitudes at equinox, it causes a strong upwelling by day accompanied by poleward winds, ultimately balanced by a similarly strong downwelling by night accompanied by equatorward winds. Because of the long time constant for thermospheric composition change, there is no net daily disturbance of thermospheric composition at low and middle latitudes, and diffusive equilibrium prevails. The consequence is that the thermosphere has a greater $[\mathrm{O} / \mathrm{N} 2]$ ratio, both in low latitudes and globally averaged, at equinox as compared to solstice (Rishbeth et al., 2000). Maps of GUVI [O/N2] with an average amplitude of the semiannual anomaly of about $\sim 0.1$ (larger at high solar activity year but not significant) at middle and low latitudes shown, in Fig. 5, support the above theory, which suggests that the variation of [O/N2] serves as a background parameter controlling the semiannual anomaly of TEC at middle and low latitudes. At high latitude, semiannual anomalies arise from the optimized effect of the solar zenith angle effect and seasonal variation of the [O/N2] ratio, 

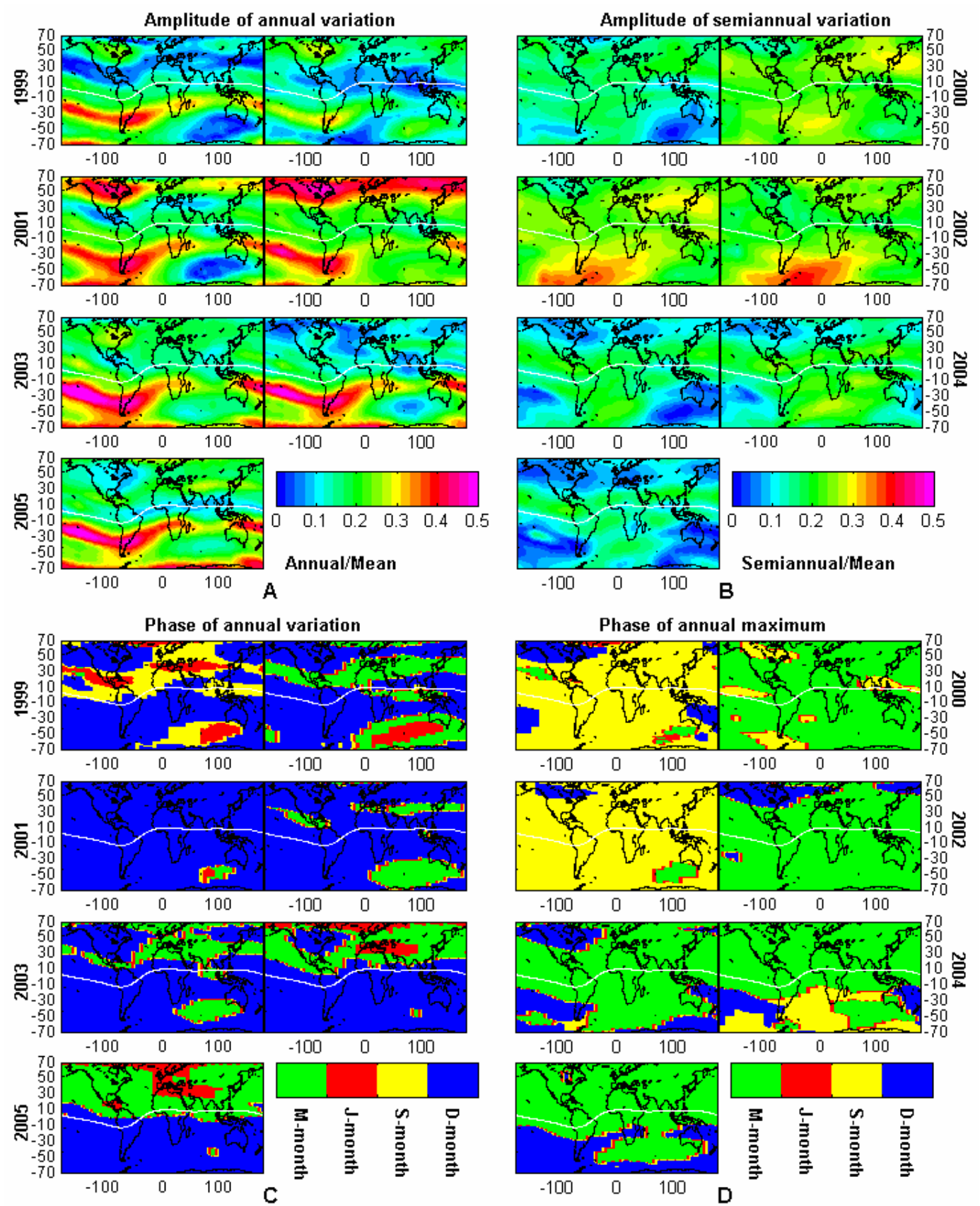

Fig. 6. Global distributions of the amplitudes of the annual and semiannual components (A, B) and the phase of the annual variation (C), and the position of the existing maximum value (D) and the amplitude of the equinox asymmetry. The white line denotes the magnetic equator (E). $x$ and $y$-axes are the geographic longitude and latitude and the white line is the dip equator.

as pointed out by Rishbeth et al. (1998), which will be discussed later in this paper.

Another possible mechanism to explain the semiannual anomaly was proposed by Lal (1998), who regards the semiannual variation of geomagnetic activity, due to the semiannual variation of geometrical coupling of the interplanetary and terrestrial magnetic fields (Russell and McPher- ron, 1973), as the cause of all semiannual aeronomic phenomena. Lal (1997) estimated that the solar EUV source can only account for $62 \%$ (equinoxes)-75\% (July) of the planetary averaged F2 layer ion density (F2pd), indicating that a second energy source is required to account for the deficit. To testify as to how the geomagnetic activity affects the TEC variation, we sum the relative change in the TEC 


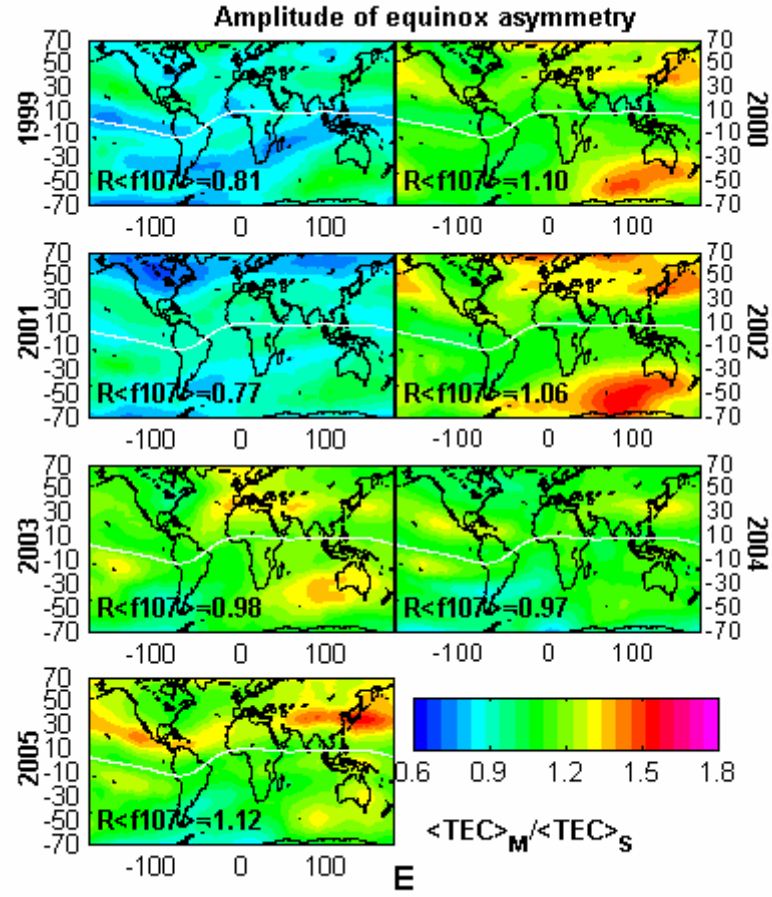

Fig. 6. Continued.

variation RTEC under the condition $A p>15$ (34.5\% of the total days) during equinox months from 2002-2005 in the MLAT-MLT coordinate. RTEC is calculated through (TEC$<$ TEC $>27$ ) $/<$ TEC $>_{27}$, where $<$ TEC $>_{27}$ is the smooth 27 day median value of TEC. For comparison, $\mathrm{R}[\mathrm{O} / \mathrm{N} 2]$ is also given with the same procedure. As shown in Fig. 7, the distribution of RTEC is well in accordance with that of $\mathrm{R}[\mathrm{O} / \mathrm{N} 2]$ from sunrise to sunset. The change in $[\mathrm{O} / \mathrm{N} 2]$ is due to the storm-induced large thermospheric circulation, which decreases [O/N2] at high latitude due to the upwelling of the polar upper atmosphere and the increase in $[\mathrm{O} / \mathrm{N} 2]$ due to the downwelling in the low and middle latitudes, and causes the abatement of TEC at high latitude and an enhancement at middle and low latitudes which is similar to the way in which the winter anomaly is produced (e.g. Mayr et al., 1978; Rishbeth et al., 1987). Here, our statistical result shows that the geomagnetic disturbance tends to decrease the ion density $(\sim 7 \%)$ at high latitudes and increase it $(\sim 6 \%)$ at middle and low latitudes. From a global view, the increased part of TEC, outweighs the decreased part of TEC which will result in a net enhancement of global TEC during the magnetic disturbed day. This may explain the results of Lal (1997), who defines a global F2 layer index. Thus, the semiannual variation of the magnetic activity tends to contribute to the semiannual anomaly of TEC at middle and low latitudes.

As illustrated in Fig. 3c, the distribution of the amplitude of the semiannual variation of TEC at low latitude has an obvious "double-humped" structure which is especially
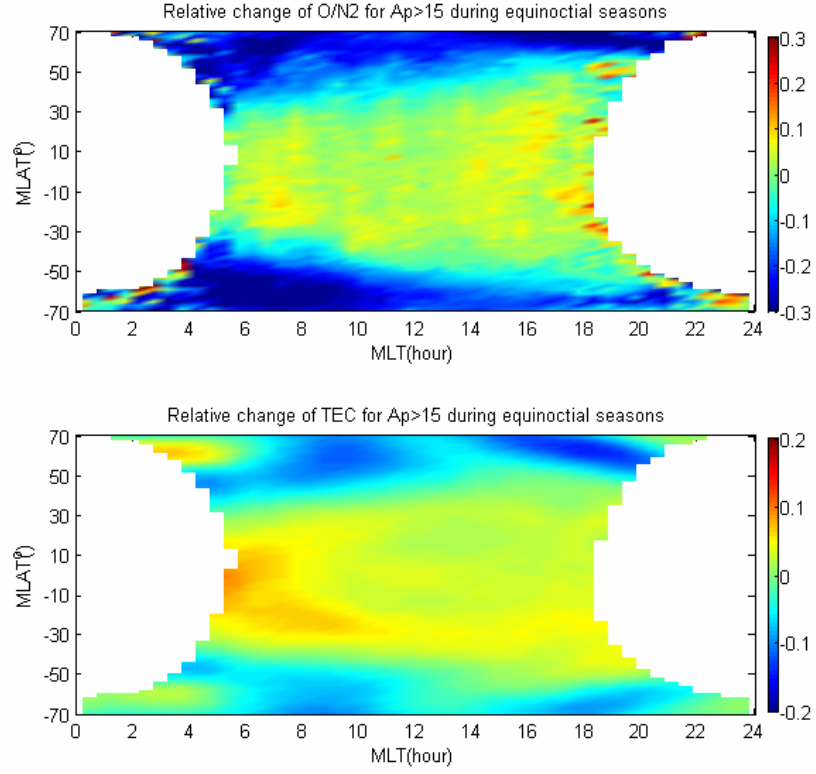

Fig. 7. Distribution of the relative change in $[\mathrm{O} / \mathrm{N} 2]$ and TEC under the condition $A p>15$ during equinoctial seasons.

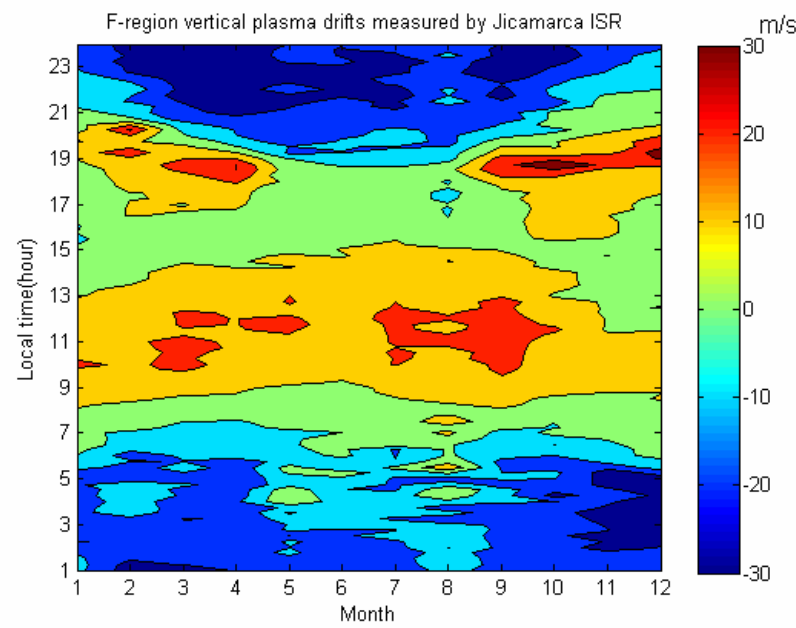

Fig. 8. Monthly average of the equatorial vertical plasma drifts measured by the Jicamarca incoherent scatter radar (ISR) in units of $\mathrm{m} / \mathrm{s}$.

strong after sunset. The structure may be related to the ionospheric fountain effect caused by the equatorial $\mathrm{E} \times \mathrm{B}$ drift. Therefore, we used average vertical drift data near the F-region peak (typically between about 300 and $400 \mathrm{~km}$ ), which was obtained from the CEDAR database at NCAR. Figure 8 shows the distribution of the monthly average vertical plasma drifts over Jicamarca, which only considers quiet time (3-hourly $a p<18$ is considered) measurements from 1984 through 2005 . The noon time and post-sunset drift is shown to be prominent at equinox months. Based on an 
empirical orthogonal functions (EOFs) analysis, a linear dependence of amplitudes of semiannual variations with F107 has been derived by Ren (2007) ${ }^{1}$. The results are consistent with early incoherent scatter radar and satellite observations which showed that the quiet time F-region vertical drifts in the equatorial area had large seasonal variations during solar maximum and minimum (Fejer, 1991; Fejer et al., 1995). Since the F-region ionosphere is electrodynamically coupled with the E-region ionosphere, the semiannual variation of the amplitude of the diurnal tide in the lower thermosphere may induce the semiannual variation of the E-region equatorial electrojet and hence affect the F-region drift. Forbes (1981) pointed out that the diurnal tide $(1,1)$ mode in the ionospheric E-layer is the direct driving source for the equatorial electrojet. The analysis of the wind data of the UARS satellite by Burrage et al. (1995) showed that there are very obvious semiannual variations of the amplitude of the diurnal tide $(1,1)$ mode at the height of $95 \mathrm{~km}$ in the period of October 1991-March 1995. Acceptance of this mechanism will require further quantitative studies and a numerical simulation study.

Besides the electric field, another way to modify the equatorial anomaly is through wind-induced drifts. Near the magnetic equator the interhemispheric wind, for example the summer to winter wind, can drive the plasma along horizontal field lines, producing north-south asymmetries in the manner described by Hanson and Moffett (1966). This transequatorial wind produces not only the asymmetry but also reduces the NmF2 at both crests of the anomaly (Bramley and Young, 1968). An uplift of the plasma at the windward crest induces an increase in plasma density, owing to the decrease in molecular gases (or decrease in $\mathrm{O}^{+}$loss rate) at higher altitudes. However, this increment does not compensate for the loss transported to the leeward crest region. In the leeward crest region, a downward drift decreases the $\mathrm{NmF} 2$ by lowering the F-layer to the height where the recombination loss rate is larger. The magnitude exceeds that transported from the windward crest, thus reducing the electron density at both crests. In addition, as has been pointed out by Burge et al. (1973), equatorward directed wind during equinox will oppose the poleward transport of ionization along the magnetic field lines. This will hinder the formation of the equatorial anomaly and increase the plasma density at equatorial areas, which may well explain the enhancement of the equatorial semiannual variation when a "doublehumped" structure disappears near midnight.

The annual anomaly remains at a long-standing, unexplained puzzle which has not been reproduced in the model simulation. The value of the global average of an "Asymmetry Index" (AI) (AI=(December-June)/(December+June)), used to characterize the amplitude of the annual anomaly is

\footnotetext{
${ }^{1}$ Ren, Z., Wan, W., Liu, L., Lei, J., and Zhao, B.: Annual and Semiannual Variations of the Ionospheric Vertical Plasma Drifts over Jicamarca, Ann. Geophys., under review, 2007.
}

far greater than the value of 0.035 that corresponds to the annual variation of the solar irradiance due to the Sun-Earth distance by using GIM data of the year 2002 (Mendillo et al., 2005). Our study shows the same results and found that the annual anomaly exists both by day and by night and is least evident in the sunrise and sunset sectors. Through the analysis on the GUVI columnar [O/N2], we found that the annual anomaly, to a considerable degree, can be explained by the north-south asymmetry of the [O/N2] during the daytime. The remaining part of the annual anomaly during the daytime and also the south-north asymmetry during the nighttime may be caused by the difference in meridional winds. By using the Hinotori satellite and Sheffield University Plasmasphere Ionosphere Model (SUPIM), Su et al. (1998) found that the difference in $[\mathrm{O} / \mathrm{N} 2]$ between December and June, obtained from MSIS-86, reproduces the general behaviour of the observed annual anomaly, but only accounts for $30 \%$ of its magnitude. The model calculations suggest that the differences between the solstice values of the neutral wind, resulting from the coupling of the neutral gas and plasma, may also make a significant contribution to the daytime annual anomaly. It has been suggested (Torr and Torr, 1973) that the Southern Hemisphere may receive more energy than the Northern Hemisphere, as a result of the asymmetry in the geomagnetic field. Since thermospheric circulation transports the neutral gases from the summer hemisphere to the winter hemisphere, the asymmetry of the energy input with respect to the equator might result in a greater energy transport to the equatorial regions from the Southern Hemisphere at the December solstice than from the Northern Hemisphere at the June solstice. Another possible energy source for the ionospheric annual anomaly is the tide in the mesosphere. There is observational evidence that the tidal intensity at the December solstice is higher than at the June solstice (Barlier et al., 1974). The energy of the tidal wave in the mesosphere can propagate upward to the thermosphere. However, recent simulations with the CTIP model have shown that including mesospheric tides in the model makes little difference to the annual anomaly. After considering possible explanations, which do not account for the asymmetry, Rishbeth and Müller-Wodarg (2006) concluded that dynamical influences of the lower atmosphere (below about $30 \mathrm{~km}$ ) are the most likely cause of the asymmetry.

\subsection{Possible mechanism of the longitude dependence of the annual and semiannual variations during daytime}

Features of the longitude dependence of the annual and semiannual variations can be explained by the current theory summarized in Rishbeth (1998). Thinking about the global ionosphere, with equinoxes being a normal state, the solstice ionosphere is distorted due to the asymmetrical atmospheric circulation. That is, at solstices there is a prevailing neutral wind blowing from the summer hemisphere to the winter one, which leads to the upwelling in the summer hemisphere, 
and the downwelling just equatorward of the auroral oval in the winter hemisphere. Thus at solstices, the upwelling in the summer hemisphere, as well as at the tropical latitudes, moves the air rich in molecules to the F2-layer and decreases $\mathrm{NmF} 2$ from the equinox value. This partly explains the semiannual anomaly that $\mathrm{NmF} 2$ is greater at equinox than at summer solstice. However, the downwelling in the winter hemisphere does not always increase $\mathrm{NmF} 2$ at solstice. In fact, at longitude sectors far from the magnetic poles (farfrom-pole), the downwelling occurs at relatively high latitudes where the solar zenith angle is very large in winter, which leads to a very weak ion production in the ionosphere. In this case the decrease of $\mathrm{NmF}$, caused by weak ion production is more important than the increase of $\mathrm{NmF} 2$ caused by the downwelling atmospheric circulation; as a result, at these longitudes, the high-latitude $\mathrm{NmF} 2$ is smaller at solstice than at equinox. This explains the semiannual anomaly that $\mathrm{NmF} 2$ is greater at equinox than at winter solstice at high latitudes and far-from-pole longitude sectors, which is consistent with our feature (4) in Sect. 3. On the other hand, at longitude sectors near the magnetic poles (near-pole), the solar zenith angle at the downwelling zone (higher midlatitudes) is not so small as that at far-from-pole longitude sectors, and the increase in $\mathrm{NmF} 2$ due to the downwelling is more important than its decrease caused by the lower ion production, due to the small solar zenith angle. In contrast, at higher mid-latitudes in this longitude sector, $\mathrm{NmF} 2$ value is greater at winter solstice, which is consistent with features (1) and (2). Using the CTIP model, Millward (1996) has shown that the large offset of the geomagnetic axis from the Earth's spin axis in the Southern Hemisphere should be responsible for the prominent semiannual variation at middle latitudes in the South American sector, as shown in the feature (5). Because of this offset, a given geographic latitude in the South American sector corresponds to a lower magnetic latitude better than in other sectors and is thus farther from the energy inputs associated with the auroral regions. As a result, the composition changes are much smaller during the winter months than at other longitudes, with the mean molecular mass being essentially constant for a 4-month period, centered on the winter solstice. In the absence of any composition changes, noon ionospheric density is influenced primarily by the solar zenith angle which reaches maximum in the winter and leads to the diminution of the ion production, a prominent minimum in $\mathrm{NmF} 2$, and therefore a remarkable semiannual variation overall.

In the Southern Hemisphere an annual component arises from the fact that the summer TEC in the South Pacific-South Atlantic region is boosted with respect to thate displayed in feature (3) and pointed out by Torr and Torr (1973). The position of this region with respect to the South Atlantic geomagnetic anomaly indicates a geomagnetic influence and a possible corpuscular component (Gledhill, 1976). Knudsen and Sharp (1968) suggest that the South Pacific enhancement may be due to energetic electrons in the tens to thousands of eV range, drifting eastward with lowering mirroring altitudes. They estimate the power input for the period of the observations to be $\sim 10^{17} \mathrm{erg} / \mathrm{s}$, a few tenths of the power input in the auroral zones during this period. This corpuscular explanation of the annual component in the South PacificSouth Atlantic regions would require that more particles be dumped in summer than in winter. However, this is probably to be expected, as in summer the atmosphere expands and thus mirroring particles will encounter more atmosphere over a wide range of altitude. This localized corpuscular precipitation in the Southern Hemisphere could also possibly enhancing convective flow to the northern winter and inhibit convection to the southern winter through a temperature gradient, thus enhances the downwelling effect and increasing the electron density in the Northern Hemisphere and reducing it in the Southern Hemisphere in the winter.

\subsection{Equinoctial asymmetry}

The existence of the equinoctial symmetry in $\mathrm{NmF} 2$ and TEC has been reported earlier by Titheridge (1973), Essex (1977) and Titheridge and Buonsanto (1983). Their studies show that the equinox of strong NmF2 and TEC (March equinox) is the same for Northern and Southern Hemispheres and at different longitudes. The mechanism of this equinoctial symmetry was not fully understood until Balan et al. (1998) carried out, for the first time, analysis using all the parameters measured by the MU radar at Shigaraki $\left(35^{\circ} \mathrm{N}, 136^{\circ} \mathrm{E}\right)$ during the solar maximum period $1988-1992$ to study the altitude dependence of plasma density asymmetry. Their results reveal that the meridional component of the daytime poleward wind velocity at $300 \mathrm{~km}$ is weaker in the March equinox than in September equinox by up to $20 \mathrm{~m} / \mathrm{s}$, and the values of the daytime $[\mathrm{O} / \mathrm{N} 2]$ ratio obtained from MSIS-86 are larger in the September equinox than in the March equinox by $20 \%$. By virtue of the SUPIM model that uses MSIS- 86 for a neutral atmosphere, Balan et al. (1998) showed that the equinoctial asymmetries in the ionosphere arose mainly from the corresponding asymmetries in the thermosphere, with major contributions from neutral winds and minor contributions from composition. However, incompatible results were given later by Richards (2001) who analyzed 9 ionosonde stations data worldwide from 1970-1980, which makes the cause of the asymmetry more complicated. In their study, no equinoctial asymmetry was found for noon $\mathrm{NmF} 2$ at non-Australia stations, even at Wakkanai $\left(45^{\circ} \mathrm{N}, 142^{\circ} \mathrm{E}\right)$ during solar maximum year 1980, with relatively smooth F107 variation. And in the Australia region, asymmetry did not exist at Townsville $\left(19^{\circ} \mathrm{S}, 147^{\circ} \mathrm{N}\right)$, a low-latitude station, and increased with increasing latitude. For those Australian stations that have clear equinoctial asymmetry, hmF2 was shown to be $\sim 25 \mathrm{~km}$ higher at the September equinox than at the March equinox. Therefore, Richards (2001) proposed that it is possible the greater $\mathrm{hmF} 2$ at the September equinox reflects a higher neutral temperature, which would decrease the atomic to 

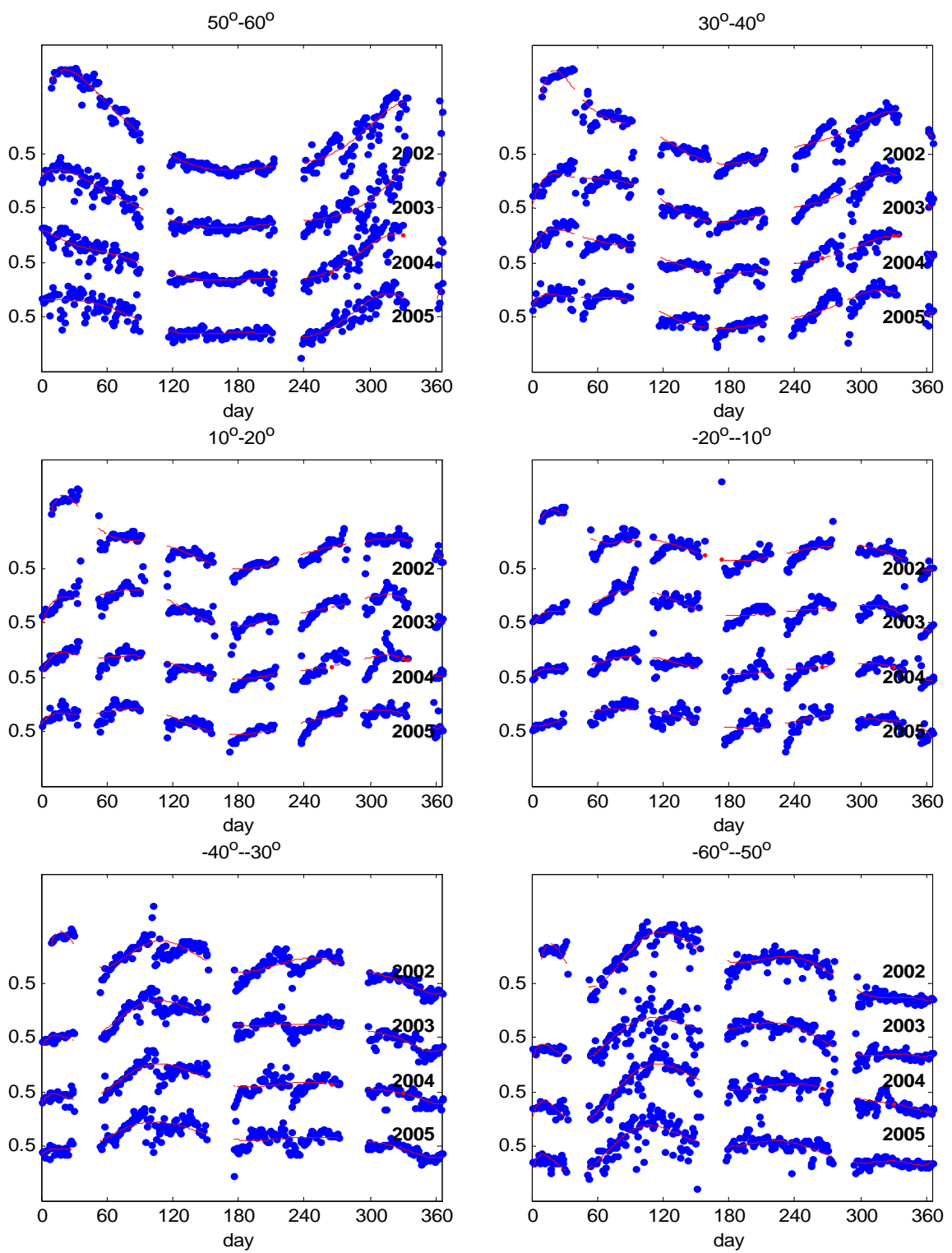

Fig. 9. Yearly variation of the GUVI measured average [O/N2] for each latitude zone during 10:00-14:00 MLT. The red line denotes the smooth value fitted according to Eq. (2).

molecular density ratio at hmF2. Such a high temperature may cause an increased circulation from the Southern Hemisphere to the Northern Hemisphere, which would then deplete the atomic oxygen density, and lower the NmF2. However, it is not clear what could cause the high temperature and why the effect should be limited to the Australian region, which leaves the neutral density composition to be the most likely explanation for the observed asymmetric peak density behavior.

To test the above assumption, we again used the GUVI [O/N2] data in the MLAT-MLT coordinate. Since the track of the satellite orbit changes everyday, corresponding to a different latitude and longitude and local time, it is impossi- ble to obtain a consecutive variation. Thus, under the premise that $[\mathrm{O} / \mathrm{N} 2]$ changes smoothly along the daytime as well as magnetic latitude, we select the zone of 10:00-14:00 MLT and $10^{\circ}$ in MLAT to calculate its mean value of [O/N2]. Actually, when we reduce the limits, the yearly trend variation of [O/N2] does not change. Figure 9 illustrates the yearly variation of the different latitudinal zone from 2002 2005. It is shown that in the Northern Hemisphere, from high latitude to low latitude, no evident equinoctial asymmetry was found in $[\mathrm{O} / \mathrm{N} 2]$. However, in the Southern Hemisphere the magnitude of the asymmetric feature increased from low latitude to high latitude significantly. The result is consistent with the conclusion of Balan et al. (1998, 2000), 
who suggested that the thermospheric wind may dominate the equinox asymmetry in the Northern Hemisphere. The result also partly supports the proposition of Richards (2001) that neutral density composition may control the asymmetric variation in the Australia area, though we use longitudinally averaged $[\mathrm{O} / \mathrm{N} 2]$. On the other hand, the difference in $[\mathrm{O} / \mathrm{N} 2]$ may imply a different wind velocity between the two equinoxes according to the mechanism that produces the winter anomaly. It is still unclear how the equinoctial asymmetric thermospheric wind originates and why it acts in different ways over the two hemispheres.

\section{Conclusions}

In this paper, we have abstracted the features of the annual and semiannual variations in TEC based on long-lasting GIM data. By organizing the data into the MLAT-MLT coordinate, the seasonal anomaly is shown to be most evident at middle to high latitudes during the local time 10:00-15:00 MLT. A semiannual anomaly exists at all the latitudes during the daytime and is most pronounced in the equatorial anomaly region and persists to midnight. An annual anomaly is also shown to prevail during both daytime and nighttime and is least evident at sunrise and sunset. The magnitude of various anomalies is shown to be clearly modulated by the solar activity. Through the comparison with the GUVI columnar $[\mathrm{O} / \mathrm{N} 2]$ data, it is shown that the seasonal, annual and semiannual variations can be explained in large part by their counterparts in $\mathrm{O} / \mathrm{N} 2$.

Features of the longitudinal dependence of the anomalies are consistent with past studies. For example, the seasonal anomaly is more significant in the near-pole regions than in the far-pole regions and the reverse is true for the semiannual anomaly. The winter anomaly has the least chance to be observed in the South America and South Pacific areas. The most interesting characteristic arises from the equinoctial asymmetry that is most prominent in the East Asian and South Australian areas and which seems to show a different dependence on $[\mathrm{O} / \mathrm{N} 2]$. Since the ionosphere can be controlled by both internal processes in the form of motions and chemical changes driven by solar radiation absorbed within the thermosphere and the external processes outside the thermosphere, like the magnetospheric disturbance or waves and tides below the ionosphere, further study needs to be carried out to investigate the major cause responsible for the various periodic variations in the ionosphere.

Acknowledgements. This research was supported by the KIP Pilot Project (kzcx3-sw-144) of Chinese Academy of Sciences, National Natural Science Foundation of China (40636032, 40725014) and National Important Basic Research Project (2006CB806306). We thank the Jet Propulsion Laboratory, California Institute of Technology for the development and operation of GIM. Special thanks should also be given to the A. B. Christensen and L. Paxton, the PI and Project Scientist of the GUVI team for providing [O/N2] data.
The Jicamarca ISR data are taken from the CEDAR Database at NCAR. NCAR is supported by the U.S. National Science Foundation. The Jicamarca Radio Observatory is a facility of the Instituto Geofísico del Perú operated with support from the NSF Cooperative Agreement ATM-0432565 through Cornell University. The authors also thank two referees for their warm suggestions.

Topical Editor M. Pinnock thanks K. Unnikrishnan and J.-Y. Liu for their help in evaluating this paper.

\section{References}

Appleton, E. V. and Naismith, R.: Some further measurements of upper atmospheric ionization, P. Roy. Soc. Lond. A, 150, 685708, 1935.

Balan, N., Otsuka, Y., Bailey, G. J., and Fukao, S.: Equinoctial asymmertries in the ionosphere and thermosphere observed by the MU radar, J. Geophys. Res., 103, 9481-9495, 1998.

Balan, N., Otsuka, Y., Bailey, G. J., Fukao, S., and Abdu, M. A.: Annual variations of the ionosphere: A review based on the MU radar observations, Adv. Space Res., 25, 153-162, 2000.

Barlier, F., Bauer, P., Jaeck, C., Thuillier, G., and Kockarts, G.: North-south asymmetries in the thermosphere during the last maximum of the solar cycle, J. Geophys. Res., 79, 5273-5285, 1974.

Bramley E. N. and Margaret Y.: Winds and electromagnetic drifts in the equatorial F2-region, J. Atmos. Terr. Phys., 30, 99-111, 1968.

Burge, J. D., Eccles, D. J., King, W., and Rüster, R.: The effects of thermospheric winds on the ionosphere at low and middle latitudes during magnetic disturbances, J. Atmos. Terr. Phys., 35, 617-623, 1973.

Burrage, M. D., Hagan, M. E., Skinner, W. R., et al.: Long-term variability in the solar diurnal tide observed by HRDI and simulated by the GSWM, Geophys. Res. Lett., 22(19), 2641-2644, 1995.

Christensen, A. B., Paxton, L. J., Avery, S., Craven, J., Crowley, G., Humm, D. C., Kil, H., Meier, R. R., Meng, C. -I., Morrison, D., Ogorzalek, B. S., Straus, P., Strickland, D. J., Swenson, R. M., Walterscheid, R. L., Wolven, B., and Zhang, Y.: Initial observations with the Global Ultraviolet Imager (GUVI) in the NASA TIMED satellite mission, J. Geophys. Res., 108, 14511466, 2003.

Codrescu, M. V., Beierle, K. L., Fuller-Rowell, T. J., Palo, S. E., and Zhang, X.: More total electron content climatology from TOPEX/Poseidon measurements, Radio Sci., 36, 325-333, 2001.

Essex, E. A.: Equinoctial variations in the total electron content of the ionosphere at northern and southern hemisphere stations, J. Atmos. Terr. Phys., 39, 645-650, 1977.

Fejer, B. G.: Low latitude electrodynamic plasma drifts: a review, J. Atmos. Terr. Phys., 53, 677-693, 1991.

Fejer, B. G., Paula, E. R., Heelis, R. A., and Hanson, W. B.: Global equatorial ionospheric vertical plasma drifts measured by the AE-E satellite, J. Geophys. Res., 100, 5769-5776, 1995.

Feltens, J. and Schaer, S.: IGS Products for the Ionosphere, in Proceedings of the IGS Analysis Center Workshop, edited by: Dow, J. M., Kouba, J., and Springer, T., 225-232, Darmstadt, 9-11 February, 1998.

Forbes, J. M.: The equatorial electrojet, Rev. Geophys. Space Phys., 19(3), 469-504, 1981. 
Fuller-Rowell, T. J. and Rees, D.: Derivation of a conservation equation for mean molecular weight for a two-constituent gas within a three-dimensional, time-dependent model of the thermosphere, Planet Space Sci., 31, 1209-1222, 1983.

Fuller-Rowell, T. J.: The "Thermospheric spoon": a mechanism for the semi-annual density variation, J. Geophys. Res., 103, 39513956, 1998.

Gledhill, J. A.: Aeronomic Effects of the South Atlantic Anomaly, Rev. Geophys. Space Phys., 14, 173-187, 1976.

Hanson, W. B. and Moffett, R. J.: Ionization transport in the equatorial F region, J. Geophys. Res., 71, 5559-5572, 1966.

Ho, C. M., Mannucci, A. J., Lindqwister, U. J., Pi, X., and Tsurutani, B.: Global ionospheric perturbations monitored by the worldwide GPS network, Geophys. Res. Lett., 23, 3219-3222, 1996.

Huang, Y.-N. and Cheng, K.: Solar cycle variations of the equatorial ionospheric anomaly in total electron content in the Asian region, J. Geophys. Res., 101, 24 513-24 520, 1996.

Jee, G., Schunk, R. W., and Scherliess, L.: Analysis of TEC data from the TOPEX/Poseidon mission, J. Geophys., Res., 109, A01301, doi:10.1029/2003JA010058, 2004.

Johnson, F. S.: Composition changes in the upper atmosphere, in: Electron Density Distributions in the Ionosphere and Exosphere, edited by: Thrane, E., North-Holland, Amsterdam, 81-84, 1964.

King, G. A. M.: The dissociation of oxygen and high level circulation in the atmosphere, J. Atmos. Terr. Phys., 21, 231-237, 1964.

Knudsen, W. C. and Sharp, G. W.: $F_{2}$ region electron concentration enhancements from inner radiation belt particles, J. Geophys. Res., 73, 6275-6283, 1968.

Lal, C.: Contribution to F2 layer ionization due to the solar wind, J. Atmos. Terr. Phys., 59, 2203-2211, 1997.

Lal, C.: Solar wind and equinoctial maxima in the geophysical phenomena, J. Atmos. Terr. Phys., 60, 1017-1024, 1998.

Liu, L., Zhao, B., Wan, W., Venkartraman, S., Zhang, M.-L., and Yue, X.: Yearly variations of global plasma densities in the topside ionosphere at middle and low latitudes, J. Geophys. Res., 112, A07303, doi:10.1029/2007JA012283, 2007.

Mannucci, A. J., Wilson, B. D., Yuan, D. N., Ho, C. M., Lindqwister, U. J., Runge, T. F.: A global mapping technique for GPSderived ionospheric total electron content measurements, Radio Sci., 33, 565-582, 1998.

Ma, R., Xu, J., and Liao, H.: The features and a possible mechanism of semiannual variation in the peak electron density of the low latitude F2 layer, J. Atmos. Solar-Terr. Phys., 65, 47-57, 2003.

Mayr, H. G., Harris, I., and Spencer, N. W.: Some properties of upper atmosphere dynamics, Rev. Geophys. Space Phys., 16, 539$565,1978$.

Mendillo, M., Huang, C.-L., Pi, X., Rishbeth, H., and Meier, R.: The global ionospheric asymmetry in total electron content, J. Atmos. Solar-Terr. Phys., 67. 1377-1387, 2005.

Millward, G. H., Rishbeth, H., Fuller-Rowell, T. J., Aylward, A. D., Quegan, S., and Moffett, R. J.: Ionospheric F2 layer seasonal and semi-annual variations, J. Geophys. Res., 101, 5149-5156, 1996.

Pi, X., Mannucci, A., Lindqwister, U. J., and Ho, C. M.: Monitoring of global ionospheric irregularities using the worldwide GPS network, Geophys. Res. Lett., 24, 2283-2286, 1997.

Richards, P. G.: Seasonal and solar cycle variations of the ionospheric peak electron density: comparison of measurement and models, J. Geophys. Res., 106(A12), 12 803-12 819, 2001.
Richmond, A. D.: Ionospheric electrodynamics using magnetic apex coordinates, J. Geomagn. Geoelectr., 47, 191-212, 1995.

Rishbeth, H. and Setty, C. S. G. K.: The F-layer at sunrise, J. Atmos. Sol. Terr. Phys., 21, 263-276, 1961.

Rishbeth, H., Fuller-Rowell, T. J., and Rees, D.: Diffusive equilibrium and vertical motion in the thermosphere during a severe magnetic storm: a computational study, planet. Space Sci., 35, 1157-1165, 1987.

Rishbeth, H.: How the thermospheric circulation affects the ionospheric F2-layer, J. Atmos. Sol. Terr. Phys., 60, 1385-1402, 1998.

Rishbeth, H., Müller-Wodarg, I. C. F., Zou, L., Fuller-Rowell, T. J., Millward, G. H., Moffett, R. J., Idenden, D. W., and Aylward, A. D.: Annual and semiannual variations in the ionospheric F2-layer: II. Physical discussion, Ann. Geophys., 18, 945-956, 2000 , http://www.ann-geophys.net/18/945/2000/.

Rishbeth, H. and Mendillo, M.: Patterns of F2-layer variability, J. Atmos. and Solar-Terr. Phy., 63, 1661-1680, 2001.

Rishbeth, H. and Müller-Wodarg, I. C. F.: Why is there more ionospheric in January than in July? The annual asymmetry in the F2-layer, Ann. Geophys., 24, 3293-3311, 2006, http://www.ann-geophys.net/24/3293/2006/.

Russell, C. T. and McPherron, R. L.: Semiannual variation of geomagnetic activity, J. Geophys. Res., 78, 92-108, 1973.

Schaer, S., Gurtner, W., and Feltens, J.: IONEX: The IONosphere Map EXchange format Version 1, in: Proceedings of the IGS Analysis Center Workshop, edited by: Dow, J. M., Kouba, J., and Springer, T., 233-247, Darmstadt, 9-11 February, 1998.

Strickland, D. J., Daniell, R. E., and Craven, J. D.: Negative ionospheric storm coincident with DE-1 observed thermospheric disturbance on October 14, 1981. J. Geophys. Res., 106, 21049 $21062,2001$.

Strickland, D. J., Meier, R. R., Walterscheid, R. L., Craven, J. D., Christensen, A. B., Paxton, L. J., Morrison, D., and Crowley, G.: Quiet-time seasonal behaviour of the thermosphere seen in the far ultraviolet dayglow, J. Geophys. Res., 109, A01302, doi:10.1029/2003JA010220, 2004.

Su, Y. Z., Bailey, G. J., and Oyama, K. I.: Annual and seasonal variations in the low-latitude topside ionosphere, Ann. Geophys., 16, 974-985, 1998, http://www.ann-geophys.net/16/974/1998/.

Titheridge, J. E.: The electron content of the southern mid-latitude ionosphere, 1965-1971, J. Atmos. Terr. Phys., 981-1001, 1973.

Titheridge, J. E. and Buonsanto, M. J.: Annual variations in the electron content and height of the $\mathrm{F}$ layer in the northern and southern hemisphere, related to neutral composition, J. Atmos. Terr. Phys., 45, 683-696, 1983.

Torr, M. R. and Torr, D. G.: The seasonal behaviour of the F2-layer of the ionosphere, J. Atmos. Terr. Phys., 35, 2237-2251, 1973.

Unnikrishnan, K., Nair, R. B., and Venugopal, C.: Harmonic analysis and an empirical model for TEC over Palehua, J. Atmos. and Solar-Terr. Phys., 64, 1833-1840, 2002.

Wright, J. W.: The F region seasonal anomaly, J. Geophys. Res., 68, 4379-4381, 1963.

Wu, C. C., Fryb, C. D., Liu, J. Y., Lioud, K., and Tseng, C. L.: Annual TEC variation in the equatorial anomaly region during the solar minimum: September 1996-August 1997, J. Atmos. and Solar-Terr. Phys., 66, 199-207, 2004. 
Yonezawa, T. and Arima, Y.: On the seasonal and non-seasonal annual variations and the semi-annual variation in the noon and midnight electron densities of the F2 layer in the middle latitudes, J. Radio Res. Lab., 6, 293-309, 1959.

Yonezawa, T.: The solar-activity and latitudinal characteristics of the seasonal, non-seasonal and semi-annual variations in the peak electron densities of the F2-layer at noon and midnight in the middle and low latitudes, J. Atmos. Terr. Phys., 33, 889-907, 1971.

Yonezawa, T.: Semi-annual variation in the peak electron densities of F2- and E-layers, J. Radiology Res. Labss, 19, 1-22, 1972.

Yu, T., Wan, W., Liu, L., and Zhao, B.: Global scale annual and semi-annual variations of daytime $\mathrm{NmF} 2$ in the high solar activity years, J. Atmos. Solar-Terr. Phys., 66, 1691-1701, 2004.
Zhao, B., Wan, W., Liu, L., Yue, X., and Venkatraman, S.: Statistical characteristics of the total ion density in the topside ionosphere during the period 1996-2004 using empirical orthogonal function (EOF) analysis, Ann. Geophys., 23, 3615-3631, 2005, http://www.ann-geophys.net/23/3615/2005/.

Zou, L., Rishbeth, H., Muller-Wodarg, I. C. F., Aylward, A. D., Millward, G. H., Fuller-Rowell, T. J., Idenden, D. W., and Moffett, R. J.: Annual and semiannual variations in the ionospheric F-layer: I. Modelling, Ann. Geophys., 18, 927-944, 2000, http://www.ann-geophys.net/18/927/2000/. 